\title{
Semiótica e leitura: o fazer-receptivo do leitor analista
}

\author{
Leandro de Oliveira NERIS (USP-FFLCH/DL)
}

RESUMO: Este trabalho tem por objetivo investigar questões concernentes à leitura e interpretação de textos literários. Propomos examinar, a partir da observação de produções escritas de alunos, mecanismos de construção do sentido que remetem ao "fazer receptivo" do leitor, concebido como feixe de estratégias do próprio texto literário.

PALAVRAS-CHAVE:Semiótica; fazer-receptivo; leitura; leitor; texto literário.

\begin{abstract}
This paper aims to investigate subjects related to the reading and interpretation of literary texts. We propose to examine, from the observation of students' written texts, mechanisms of meaning construction that refer to the reader's receptive doing, conceived as a group of strategies pertaining to the literary text.
\end{abstract}

KEYWORDS: Semiotics; receptive-doing; reading; reader; literary text. 


\section{Introdução}

\begin{abstract}
"Eis então que o (romancista) desencadeia em nós, durante uma hora, todas as venturas e todas as desgraças possíveis, algumas das quais levaríamos anos para conhecer na vida, e outras as mais intensas dentre elas, jamais nos seriam reveladas, pois a lentidão com que se processam nos impede de as perceber (assim muda nosso coração, na vida), e esta é a mais amarga das dores; mas é uma dor que só conhecemos pela leitura". PROUST, $\mathrm{M}$.
\end{abstract}

Após uma trajetória de estudos de textos orientada por práticas pedagógicas vigentes nas escolas brasileiras, os alunos deveriam desenvolver certas competências e habilidades para a leitura e interpretação textual. Dessa maneira, um aluno em seu último ano de ensino médio, por meio da competência de interpretação adquirida ao longo do percurso escolar, deveria possuir um "saber-interpretar" os mais diversos tipos de textos. Nessa esteira, desenvolver um estudo relativo à leitura, implica colocar o sujeito leitor e intérprete no centro de nossas preocupações e retomar inquietações importantes no que tange às competências dos alunos para ler e interpretar.

De acordo com estudos desenvolvidos por Fiorin, o ensino de leitura e interpretação, tal qual vem sendo praticado na grande maioria das escolas parece não ter ainda assimilado os progressos feitos pelas teorias lingüísticas

A aula de interpretação consiste em responder a um questionário com perguntas que não representam nenhum desafio intelectual ao aluno e que não contribuem para o entendimento global do texto. Muitas vezes o professor não se satisfaz com os textos e os roteiros de interpretação dos livros didáticos, seleciona algum texto e faz uma bela interpretação em classe. Se um aluno lhe pergunta como enxergar numa produção discursiva as coisas geniais que ele nela percebeu, costuma apresentar duas respostas: para analisar um texto é preciso ter sensibilidade; para descobrir os sentidos dos textos, é necessário lêlos uma, duas, três, n vezes. (FIORIN, 1997: 09)

Nesse sentido, este trabalho tem por objetivo apresentar reflexões concernentes à leitura e interpretação de textos literários por alunos da $3^{\mathrm{a}}$ série do ensino médio. Dessa forma, nossa investigação tem como intuito observar como se dá o processo de leitura de textos literários e de que forma é estabelecida a relação entre sujeito leitor e o texto. Para tanto, uma das maneiras encontradas para averiguarmos como ocorre o ato de ler, foi o de analisar textos interpretativos escritos por leitores. Estabelece-se, então, uma maneira de compreender o processo de leitura, ou seja, de entender pela relação texto matriz e texto analítico do aluno leitor o que ocorre no ato de leitura. 
Embora este trabalho esteja pautado em uma pesquisa sobre leitura na escola, não a abordaremos do ponto de vista da prática pedagógica, buscando encontrar razões para a problemática da crise da leitura, nem encontrar formas de ensinar ou aprender a ler baseadas em práticas didáticas variadas. Este trabalho justifica-se por propiciar reflexões teóricas que explicitem o papel da leitura diferentemente daquele voltado ao posicionamento dos que seguem um percurso de estudo de discursos sobre a leitura ancorados em pesquisas históricas para poder entender como deve ser seu processo, mas ao contrário, busca analisar o que se lê e como se lê por meio dos textos.

\section{Por um percurso teórico}

Convém estabelecermos, portanto, os parâmetros teóricos que guiam a realização de nosso estudo. Este trabalho teve, então, como suporte teórico a Teoria Semiótica da escola semiótica de Paris e elementos dos estudos de D. Maingueneau e de M. Bakhtin.

Para a teoria semiótica, a leitura é essencialmente uma semiose, uma atividade primordial cujo resultado é correlacionar um conteúdo a uma expressão dada e transformar uma cadeia de expressão em uma sintagmática de signos. Tal performance pressupõe uma competência do leitor, comparável, ainda que não necessariamente idêntica, à do produtor do texto. Se, no momento da leitura normal, o fazer receptivo e interpretativo do enunciatário-leitor continua implícito, sua explicitação, sob forma de procedimentos de análise estabelecidos, tendo em vista a reconstrução do sentido, constitui tarefa da semiótica. Nessa perspectiva, entende-se por leitura a construção, ao mesmo tempo sintáxica e semântica, do objeto semiótico que explica o texto-signo. (GREIMAS, COURTÉS, s/d [1983]: 251-252).

A partir deste conceito estabelecido pela semiótica, julgamos necessário distinguir, inicialmente, duas posições frente à leitura. Uma que observa o leitor inscrito no texto, visto pela semiótica como a figura do enunciatário, e outra voltada para a ação, considerando o leitor externo ao texto no ato de leitura.

O enunciatário é visto em semiótica não como o leitor real, mas como o destinatário implícito da enunciação. Dessa forma, são os elementos do próprio texto que proporcionam o contorno desse leitor a partir de características discursivas. Ele passa a ser, então, co-enunciador, já que vai determinar a escolha dos elementos que irão compor o texto. O enunciatário-leitor não é, então, apenas o destinatário da comunicação, mas também sujeito produtor do discurso, por ser a leitura um ato de linguagem (um ato de significar) da mesma maneira que a produção do discurso propriamente dita. Ainda, citando Maingueneau (1996: 32) "é o co-enunciador que enuncia a partir das indicações cuja rede total constitui o texto da obra". Dessa forma, duas formas lingüísticas estão presentes na enunciação: o sujeito gerador do discurso, o enunciador, e aquele para quem se dirige esse mesmo discurso, o enunciatário.

$\mathrm{O}$ enunciatário, manipulado cognitiva e pragmaticamente pelo enunciador, cumpre os papéis de destinatário sujeito, ainda que o fazer pretendido não se realize. $\mathrm{O}$ fazer interpretativo do enunciatário que responde ao fazer persuasivo do enunciador ocorre também no discurso-enunciado. $\mathrm{O}$ enunciador propõe um contrato que estipula como o enunciatário deve interpretar a verdade do discurso. 
A interpretação depende, assim, da aceitação do contrato fiduciário e, sem dúvida, da persuasão do enunciador para que o enunciatário encontre as marcas de veridicção do discurso e as compare com seus conhecimentos e convicções, decorrentes de outros contratos de veridicção, e creia, isto é, assuma as posições cognitivas formuladas pelo enunciador. $\mathrm{O}$ enunciador não produz discursos verdadeiros ou falsos, mas constrói discursos que criam efeitos de sentido de verdade ou de falsidade, que parecem verdadeiros. $\mathrm{O}$ parecer verdadeiro é interpretado como ser verdadeiro, a partir do contrato de veridicção assumido. (BARROS, 1988: 94)

Não obstante, como explicita Barros (2001), nos seus desenvolvimentos mais recentes a semiótica tem procurado conciliar, com o mesmo aparato teóricometodológico, as análises ditas "interna" e "externa" do texto. Para explicar "o que o texto diz", a semiótica trata de examinar os procedimentos de organização textual e, ao mesmo tempo, os mecanismos enunciativos de produção e recepção do texto".

O segundo posicionamento é aquele que explicita os mecanismos de recepção do texto, ou seja, o processo de leitura em ato, captando o leitor, em seu fazerinterpretativo como o principal modo de funcionamento da competência epistêmica.

Assim como diz Cortina, "a semiotização do ato de leitura se dá na medida em que se examina o movimento significativo instaurado pela relação entre o enunciado e o sujeito social da leitura". (CORTINA, 2004: 186).

Dessa forma, torna-se necessário observar como os leitores reconhecem o discurso manifesto por meio da construção do percurso de leitura, isto é, qual é o reconhecimento das instâncias produtoras do texto. Desse ponto de vista, se para a semiótica o leitor real está fora de seu horizonte teórico, deve-se tentar apreendê-lo, "semiotizar o ato de leitura" estudando o fazer-receptivo sob a descrição semiótica.

A partir das considerações expostas, julgamos importante dizer, ainda, que esse estudo teve a pretensão de verificar, a partir do fazer-receptivo/interpretativo do aluno, posições frente ao crer que os textos literários implicam e constroem e a imagem (ethos) do leitor de textos literários como enunciador de um texto analítico.

\section{O fazer-receptivo do leitor/analista}

Inicialmente, convém estabelecer parâmetros que situem a realização deste trabalho. Foram coletadas, no início da pesquisa, interpretações escritas produzidas pelos alunos a partir da leitura do conto "Presente dos Magos" do escritor norteamericano O. Henry. O gênero conto foi escolhido por se tratar de uma pesquisa aplicada na escola de ensino médio e julgamos que seria mais viável a utilização de um texto curto para a coleta de dados.

Foram recolhidas, dessa forma, vinte e cinco produções escritas, o que forma uma totalidade discursiva, isto é, uma classe de alunos leitores. Neste breve trabalho, escolhemos apenas uma, para representar nossas discussões. Buscaremos, então, mecanismos que concretizem o fazer interpretativo que diz respeito ao sujeito da enunciação, bipartido em enunciador e enunciatário. No caso, o fazer interpretativo de um leitor escolar, um aluno ao qual foi solicitada a leitura do conto. 
Examinamos, a partir da observação da produção escrita escolhida, mecanismos de construção do sentido que remetem ao "fazer receptivo" do leitor, concebido como feixe de estratégias do próprio texto literário. Por meio desse texto analítico/interpretativo do aluno, tencionamos, portanto, observar: a) o olhar do leitor que se circunscreve à aparência textual ou o olhar que desce e busca na imanência discursiva mecanismos de construção de sentido; b) como o aluno produziu um texto que dialoga com o texto de O. Henry; c) as vozes convergentes e vozes divergentes em relação ao conto; d) a imagem de si mesmo que este aluno constrói como ethos ao textualizar e discursivizar sua análise, o convicto, o hesitante, o sujeito orientado pela paixão da indiferença.

Dessa maneira, a relação estabelecida entre o leitor e o texto é um dos pontos de grande relevância neste trabalho, uma vez que o processo desencadeado pelo ato de leitura nos remete à produção de sentidos que podem ser apreendidos por meio das interpretações escritas feitas pelos leitores.

Queremos demonstrar, se bem que de maneira superficial, alguns mecanismos de recepção do texto de O. Henry. Devemos, então, estabelecer uma relação entre o conto analisado e a interpretação feita a partir desse conto. Para isso, analisamos o texto de interpretação como um outro texto que dialoga com o texto de O. Henry, isso nos leva a tentar entender como a interioridade - estruturas do texto do aluno - foi concebida em função de uma exterioridade - texto literário de O. Henry.

Devemos resgatar, portanto, o termo dialogar que alude diretamente a $\mathrm{M}$. Bakhtin, estudioso precursor do dialogismo da linguagem,atestando que "sob as palavras de alguém ressoa a voz de outrem." (BAKHTIN, 1979: .238-64). Então, restanos observar as palavras de O. Henry que ressoam nas palavras do aluno enquanto produtor de textos. Falamos, neste caso, de heterogeneidade constitutiva, uma vez que o discurso do aluno foi (é) constituído por outros discursos, confirmando quando Bakhtin diz que "a orientação dialógica é um fenômeno característico de todo discurso." (idem)

Ler é produzir um texto que tem como referente um outro texto. A leitura e a interpretação são constituídas por uma relação intertextual, ou seja, um texto que remete a outro, que é a sua razão de ser. A interioridade do discurso do aluno deve ser concebida, então, pela sua relação com a exterioridade.

Produção escrita - texto analítico de um aluno da $3^{\mathrm{a}}$ série do ensino médio tendo como suporte para leitura o conto "Presentes de Reis Magos"do escritor O. Henry.

Presentes de Reis Magos é um texto que nos mostra a dificuldade de dois jovens, que fazem de tudo para agradar um ao outro.

Moram em um pequeno apartamento, mobiliado por apenas oito dólares semanais, bem pobre.

A história que ocorre na véspera de Natal, nos passa a mensagem de companheirismo, o sacrifício que às vezes passamos para agradar as pessoas que gostamos muito. 
Mas, infelizmente, o sacrifício que Della fez por Jim - o de cortar o seu lindo cabelo - não vale a pena; já que a corrente de platina que serviria como suporte para o belo relógio de Jim, de nada serviria; infelizmente ele havia vendido seu relógio para também agradar sua esposa.

Della ganha o presente que tanto queria, os pentes que tanto namorara na vitrine da loja; enquanto seu marido acabou com um presente que parecia ser bonito, mas de nada serviria.

Mas o que realmente importa, nem sempre é o presente si, mas sim a intensão, o amor, o carinho que leva a pessoa a dá-lo.

A partir desse texto interpretativo, pudemos detectar e assinalar os pontos de estímulo dados pelo texto de O. Henry percebidos por nosso leitor. Os componentes do texto, tal como descritos por meio do percurso gerativo do sentido, provocaram determinadas reações e guiaram a leitura. Acreditamos nós, analistas, que, com o instrumental do percurso gerativo do sentido, pode ser observado como e por que nosso leitor observou temas e figuras do discurso, como a questão da pobreza, do sacrifício e da abdicação dos bens materiais em virtude do amor. Como temas e figuras se articulam a todos os níveis de geração do sentido, todos esses níveis estarão implicados para que se descreva o ato de recepção, a leitura. Essa é a nossa proposta: descrever empírica e não intuitivamente o processo de leitura, tido como recepção.

Essas questões assinaladas pelo aluno/leitor são condicionadas pela própria estrutura do texto. Essas estruturas dizem respeito às três dimensões privilegiadas pelo discurso literário: narrativa, passional e figurativa. As estruturas do texto são entendidas como a matriz básica para a interação entre texto e leitor. $\mathrm{O}$ ponto de vista do leitor não pode proceder arbitrariamente. O leitor precisa orientar-se no texto, para poder realizar sua leitura. Dessa forma, por meio do outro texto, pela emissão de um fazer interpretativo que sancionou o fazer discursivo do enunciador, esse leitor faz um julgamento do fazer discursivo do escritor pelo final opinativo presente em seu texto analítico. A leitura pode ser entendida, então, como um processo de interpretação que sanciona o fazer do texto, quer pela investigação de sua estrutura interna, quer pela relação estabelecida com o macrotexto cultural.

A constituição do texto do aluno se dá através do entrelaçamento de seu universo de consciência discursiva com o do texto lido, isto é, o aluno interpreta o texto de acordo com suas experiências de mundo. A produção interpretativa do aluno é sustentada no texto que lhe deu origem. A questão da pobreza observada foi condicionada pelo percurso figurativo que aparece no texto: pechinchando, economizado tostão por tostão, pequeno sofá puído, puído tapete vermelho, velho casaco marrom, velho chapéu marrom. O sacrifício foi verificado pelo percurso passional que explicita a relação dos sujeitos e seus objetos, em que os sujeitos tiveram que vender o que tinham de mais valioso para agradar um ao outro. Por fim, a abdicação dos bens materiais foi observada no final do conto, pois os objetos foram deixados de 
lado e o que imperou foi o amor de um pelo outro. $\mathrm{O}$ aluno leitor expressa tal reconhecimento pelas citações:"o sacrifício que às vezes passamos", "o sacrifício que Della fez por Jim".

Ademais, o texto de O. Henry incorpora elementos figurativos que fazem com que o leitor analisado seja levado a aderir ao texto. O enunciador, por seu fazer persuasivo, condiciona o fazer interpretativo do enunciatário/leitor e a construção do simulacro da verdade está ligado ao universo axiológico, tanto do enunciador quanto do enunciatário.

Além disso, a adesão de credulidade assumida faz com que os leitores sofram com as personagens e o leitor demonstra um crer e assume sua crença se fundindo com ela.

Notamos, portanto, como diz Bertrand,

O leitor deixa-se absorver por uma espécie de segunda visão, deixa-se levar com plena confiança, age e sofre com as personagens, quer a continuação e se apressa em direção ao fim, consente em aderir a sua alucinação momentânea e, ao crer nela, ele se vê dentro dela. (BERTRAND, 2003: 407)

\section{Um saber-parafrasear}

Queremos especificar, nesse momento de nosso trabalho, o olhar do leitor que se circunscreve à aparência textual ou o olhar que desce e busca na imanência discursiva mecanismos de construção de sentido. Em nossa amostra, o aluno não apresentou indícios de um apoio em um aparato teórico-metodológico adequado para descrever a gramática interna do texto. Ele apresentou suas reais competências adquiridas ao longo do percurso escolar para interpretar o texto literário proposto. Tais competências dizem respeito, fundamentalmente, a um "saber parafrasear", em que não há uma análise da linguagem.

Presentes de Reis Magos é um texto que nos mostra a dificuldade de dois jovens, que fazem de tudo para agradar um ao outro.

Moram em um pequeno apartamento, mobiliado por apenas oito dólares semanais, bem pobre.

A história que ocorre na véspera de Natal, nos passa a mensagem de companheirismo, o sacrifício que às vezes passamos para agradar as pessoas que gostamos muito.

De acordo com Greimas e Courtés (s/d [1983]: 326):

A paráfrase deve ser concebida como um dos dois modos de produção e de reconhecimento da significação e mais precisamente, como o modo paradigmático, em oposição ao modo sintagmático, que consistiria na sua apreensão enquanto intencionalidade. 
Para poder parafrasear, os alunos tiveram que "reconhecer" a narratividade presente no texto, isto é, foi necessário "o reconhecimento de uma organização imanente (ou da narratividade). (Greimas \& Courtés, s/d [1983]:295). Dessa forma, para poder ler e produzir, os alunos/leitores devem possuir "pressupostamente uma competência narrativa para dar conta da produção e recepção dos discursos ocorrências" (Greimas \& Courtés, s/d [1983]:296)

Atentando mais para a questão, notamos que a paráfrase é um formular de uma outra maneira o conteúdo equivalente de uma unidade significativa no interior de uma semiótica dada. Ela é vista por nós, então, como uma figura que marca a heterogeneidade do discurso dos alunos.

\section{Em busca do ethos do leitor/analista}

As formas de percepção estão condicionadas pelo grupo social a que o sujeito está ligado. $\mathrm{Na}$ interpretação selecionada, há um final opinativo, como se o "eu" se instituísse e falasse e não apenas observasse e relatasse fatos de fora. Neste ponto há uma tomada de atitude e um posicionamento. O produtor como que se impõe, parece querer estabelecer um diálogo com o leitor e dizer o que pensa.

"Mas o que realmente importa"

Este leitor tenta compensar um estado de falta presente no conto e, para isso, constrói um simulacro da completude do sujeito realizado que supõe paixões tais como: satisfação e alegria.

"Mas o que realmente importa nem sempre é o presente, mas sim a intenção, o amor, o carinho que leva a pessoa a dá-lo."

Neste ponto de nossa análise, queremos observar como se constrói a imagem do enunciador, isto é, do ator da enunciação inscrito no texto interpretativo analisado. Podemos tentar delinear, se bem que de maneira superficial, o ethos do analista do conto de O. Henry, orientado pela ideologia do senso comum, que supõe o acabamento e a transparência do sentido nas relações discursivas. Há um ethos incompatível com a falta patêmica (passional), dada a construção de mundo por meio da crença na possibilidade de completude do indivíduo. Há, dessa maneira, um aligeiramento da prática de leitura, um modo reducionista de preenchimento das reticências que compõem todo e qualquer texto, o que constrói o contexto escolar no texto de leitura escolar. Temos, então, as formações ideológicas que ditam o que pensar para o estudante de $2^{\circ}$. Grau. Pensar num mundo dado segundo a inevitável e obrigatória harmonização das trocas sociais.

O ethos do texto de leitura escolar é um testemunho de um tempo (século XXI) e de um espaço (instituição escolar) que viabiliza um aparato simbólico segundo o qual o homem não-quer, não-pode, não-sabe conviver com a falta e a dor provocada por ela. O tema da falta é, dessa forma, rejeitado e disforizado pelo leitor. $\mathrm{O}$ aluno interpreta os valores inscritos no discurso do sujeito produtor de acordo com sua visão ética, ou seja, de acordo com os valores de sua formação ideológica, condizente com a manifestação das paixões, valores, interesses e atitudes de nossa sociedade. 


\section{REFERÊNCIAS BIBLIOGRÁFICAS}

AMOSSY, Ruth. (org). Imagens de si no discurso. A construção do ethos. São Paulo: Contexto, 2005.

BARROS, Diana Luz Pessoa. Teoria do discurso: fundamentos semióticos. São Paulo: Atual, 1988.

Teoria semiótica do texto. São Paulo: Ática, 1994.

.Estudos do discurso. In: FIORIN, J. L. (Org). Introdução à lingüística. II. Princípios de análise. São Paulo: Contexto, 2003.

BERTRAND, Denis. Caminhos da semiótica literária. São Paulo: Edusc, 2003.

CHARAUDEAU, Patrick.; MAINGUENEAU, Dominique. Dicionário de Análise do Discurso. São Paulo: Contexto, 2004.

CORTINA, Arnaldo. Semiótica e leitura: os leitores de Harry Potter. In: CORTINA, Arnaldo.; MARCHEZAN, Renata Coelho. (Orgs.) Razões e sensibilidades: A semiótica em foco. Araraquara: Laboratório Editorial/FCL/UNESP; São Paulo: Cultura Acadêmica Editora, 2004.

. Leitura como processo de compreensão e de interpretação. O príncipe e seus leitores. São Paulo: FFLCH/USP. Tese de doutorado, 1994.

O texto e o leitor. Um problema de interpretação. São Paulo: FFLCH/USP. Dissertação de mestrado. 1988.

COURTÉS, Joseph. Introdução à semiótica narrativa e discursiva. Coimbra: Almedina, 1979.

DISCINI, Norma. Intertextualidade e conto maravilhoso. São Paulo: Humanitas/FFLCH/USP, 2002.

. O estilo nos textos: histórias em quadrinhos, mídia e literatura. São Paulo: Contexto, 2003.

2005.

A comunicação nos textos: leitura, produção e exercícios. São Paulo: Contexto,

. HQ e charge. In: LOPES, Ivã Carlos.; HERNANDES, Nilton. (Orgs). Semiótica.

Objetos e práticas. São Paulo: Contexto, 2005.

ECO, Umberto. Leitura do texto literário. Lector in fabula: a cooperação interpretativa nos textos literários. Trad. BRITO, M. Lisboa: Editorial Presença, 1983.

FIORIN, José Luiz.; SAVIOLI, Francisco Platão. Para entender o texto. $3^{\mathrm{a}}$. ed. São Paulo: Ática, 1991.

FIORIN, José Luiz. Elementos de análise do discurso. São Paulo: Contexto- Edusp, 1989.

. As astúcias da enunciação. São Paulo: Ática, 1996.

. Teorias do discurso e ensino da leitura e da redação. In: GRAGOATÁ. O ensino de língua e da literatura. Revista do Instituto de Letras - Programa de Pós-Graduação. Niterói: EDUFF, nº 2, $1^{\circ}$ semestre, 1997.

. O Pathos do Enunciatário, (artigo xerocado), 2004. 
O Ethos do enunciador. In: CORTINA, Arnaldo.; MARCHEZAN, Renata Coelho (Orgs.) Razões e sensibilidades: A semiótica em foco. Araraquara: Laboratório Editorial/FCL/UNESP; São Paulo: Cultura Acadêmica Editora, 2004.

FONTANILLE, Jacques. Sémiotique et littérature: essais de méthode. Paris: PUF, 1999.

GREIMAS, Algirdas Julien.; FONTANILLE, Jacques. Semiótica das paixões. Dos estados de coisas aos estados de alma. São Paulo: Ática, 1993.

GREIMAS, Algirdas Julien.; COURTÉS, Joseph. Dicionário de semiótica. São Paulo: Cultrix, s/d [1983]).

MAINGUENEAU, Dominique. Pragmática para o discurso literário. São Paulo: Martins Fontes, 1996.

. O contexto da obra literária. São Paulo: Martins Fontes, 2001.

. Elementos de lingüística para o texto literário. São Paulo: Martins Fontes, 2001.

PROPP, Vladmir. Morfologia do conto. Lisboa: Veja, 1983.

RIFATERRE, Michel. A produção do texto. São Paulo: Martins Fontes, 1989. . Estilística estrutural. São Paulo: Cultrix, 1973.

\section{Como citar este artigo:}

NERIS, Leandro de Oliveira. Semiótica e leitura: o fazer-receptivo do leitor analista. Estudos Semióticos, Número 2, São Paulo, 2006.

Disponível em <www.fflch.usp.br/dl/semiotica/es>. Acesso em "dia/mês/ano". 